\title{
Infectious complications after heart transplantation
}

\author{
DKC COOPER, RP LANZA, S OLIVER, AA FORDER, AG ROSE, CJ UYS, D NOVITZKY,
} CN BARNARD

From the Departments of Cardiac Surgery, Medical Microbiology, and Pathology, Groote Schuur Hospital and University of Cape Town Medical School, Cape Town, South Africa

ABSTRACT Infection has been the major cause of death and morbidity in patients undergoing cardiac transplantation at Groote Schuur Hospital. Twenty-two (55\%) patients suffered at least one major episode of infection, which accounted for $10(59 \%)$ of the deaths in the first year. The $N$ major site of origin of infection was the lung, though dissemination was not infrequent. Bacteria 을 accounted for $22(59 \%)$ infections; but viral, fungal and protozoal infections were not uncommon and in fact accounted for seven $(64 \%)$ of the fatal infections. Several unusual causative microorganisms have been isolated in this group of immunocompromised subjects. There is a higher incidence of infection in patients over the age of 35 years and in patients who did not comply with instructions and advice.

Infection is the major cause of death in patients undergoing cardiac transplantation, especially in the first few months when immunosuppression is heaviest. ${ }^{2}$ Patients are susceptible to infection by a wide range of pathogens, bacterial infection being by far the most common; other organisms primarily responsible include viruses, fungi, and protozoa. ${ }^{3}$ We report our experience with such infections in recipients of heterotopic heart transplants over the past seven years.

\section{The patients}

From 25 November 1974 to 29 October 198144 heterotopic heart transplants were performed in 40 patients, four patients undergoing retransplantation after irreversible rejection; all have been followed up for at least five months. Details of the selection and management of patients have been described previously. $^{2}$

The basic immunosuppressive treatment throughout this period has consisted of: (1) azathioprine at the highest tolerated level as judged by the absence of bone marrow and hepatic toxicity, the maintenance dose for adults being $1.5-4.0 \mathrm{mg} / \mathrm{kg} /$ day; (2)

Address for reprint requests: Mr DKC Cooper FRCS, Department of Cardiac Surgery, University of Cape Town Medical School, Observatory 7925, Republic of South Africa.

Accepted 20 July 1983 methylprednisolone $600 \mathrm{mg}$ given intravenously on the day of operation and reduced by daily increments of $100 \mathrm{mg}$ until discontinued on the sixth postoperative day, after which time oral doses of 64 $\mathrm{mg} /$ day have been administered, reducing to about $32 \mathrm{mg} /$ day at three months if the progress of the patient permits; (3) from 1970 to 1979 equine antilymphocyte globulin was given intravenously during the first month, in doses related to its effect on $T$ cell rosetting; rabbit antithymocyte globulin has been used since mid-1979. Acute rejection episodes have been treated with three to five daily intravenous pulses of methylprednisolone and short courses of RATG and/or actinomycin D (200 $\mu \mathrm{g}$ )day for 3 to 4 days).

Attention was paid to the location and elimination of all sources of infection before transplantation. 옥 Patients with active infection or conditions which $\supset$ might predispose to infection, such as diabetes mellitus requiring insulin, were not selected for trans- $N$ plantation. Perioperative antibiotic prophylaxis at $\sigma$ the time of transplantation consisted of cephaman- $N$ dole nafate $1 \mathrm{~g}$ intravenously on induction of anaesthesia, followed by $1 \mathrm{~g}$ intravenously six hourly for $\bar{O}$ four days. After transplantation observation for clin-co ical symptoms and signs of infection was continuous, $\stackrel{\overparen{D}}{\overparen{D}}$ laboratory investigation urgent and intense, and $\stackrel{\odot}{\rightarrow}$ treatment aggressive. Specific treatment was with- $\square$ held until the infecting organism had been positively identified, unless identification proved impossible in life threatening conditions. 
Table 1 Primary cause of death after heterotopic heart transplantation in 28 patients

\begin{tabular}{lllll}
\hline Cause of death & \multicolumn{4}{c}{ Months after transplantation } \\
\cline { 2 - 4 } & $\leqslant 3$ & $3-12$ & $>12$ & \multicolumn{1}{c}{$\begin{array}{c}\text { Total } \\
\text { No }(\%)\end{array}$} \\
\hline Acute rejection & 2 & 0 & 1 & $3(11)$ \\
Infection & 7 & 3 & 1 & $11(39)$ \\
Graft atherosclerosis & 0 & 1 & 6 & $7(25)$ \\
Other & 3 & 1 & 3 & $7(25)$ \\
\cline { 2 - 5 } Total No (\%) & $12(43)$ & $5(18)$ & $11(39)$ & $28(100)$ \\
\hline
\end{tabular}

\section{Results}

\section{CAUSES OF DEATH}

Of 40 patients in this series, 28 have subsequently died. Survival ranged from one day to over four years. Survival of those who remain alive extends from 5 months to over 7 years. The primary causes and timing of death are given in table 1 . Infection accounted for $11(39 \%)$ of the deaths and was the major cause of death in the first year after transplantation, when it accounted for $10(59 \%)$ of the 17 deaths.

\section{OVERALL INFECTION}

Twenty two patients $(55 \%)$ suffered at least one major episode of infection. The cause was bacterial in $22(59 \%)$, viral in $8(22 \%)$, fungal in $5(14 \%)$, and protozoal in $2(5 \%)$. Disseminated and pulmonary infections accounted for over half of all episodes.

\section{FATAL INFECTIONS}

The number and type of fatal infections and the organisms responsible are shown in table 2 . With two exceptions, all were or became disseminated. At least seven fatal infections originated in the lungs, two remaining confined there. Only one fatal infection occurred after the first year. Several of the organisms cultured from these patients were of doubtful significance, though determination of significance is a recurring problem in immunosuppressed patients.

All four fatal bacterial infections occurred within three months of transplantation and two occurred in patients who had undergone retransplantation. Fungal infections in general developed later after transplantation. Fatal viral infection was seen both early and late.

Though bacteria accounted for $59 \%$ of all fatal and non-fatal infections, fungi and viruses accounted for $64 \%$ of all fatal infections (seven of 11). Indeed, three of four fungal infections were fatal, reflecting the great difficulty experienced in eradicating these organisms in immunosuppressed patients.

Gas gangrene of the leg occurred in one patient, amputation being unsuccessful in delaying death. The source of the Clostridium perfringens was uncertain, but possibly followed an endomyocardial biopsy performed through the femoral vein a few days previously. At necropsy the organism was also grown from the lungs.

Table 2 Fatal infections in 11 patients after heterotopic cardiac transplantation

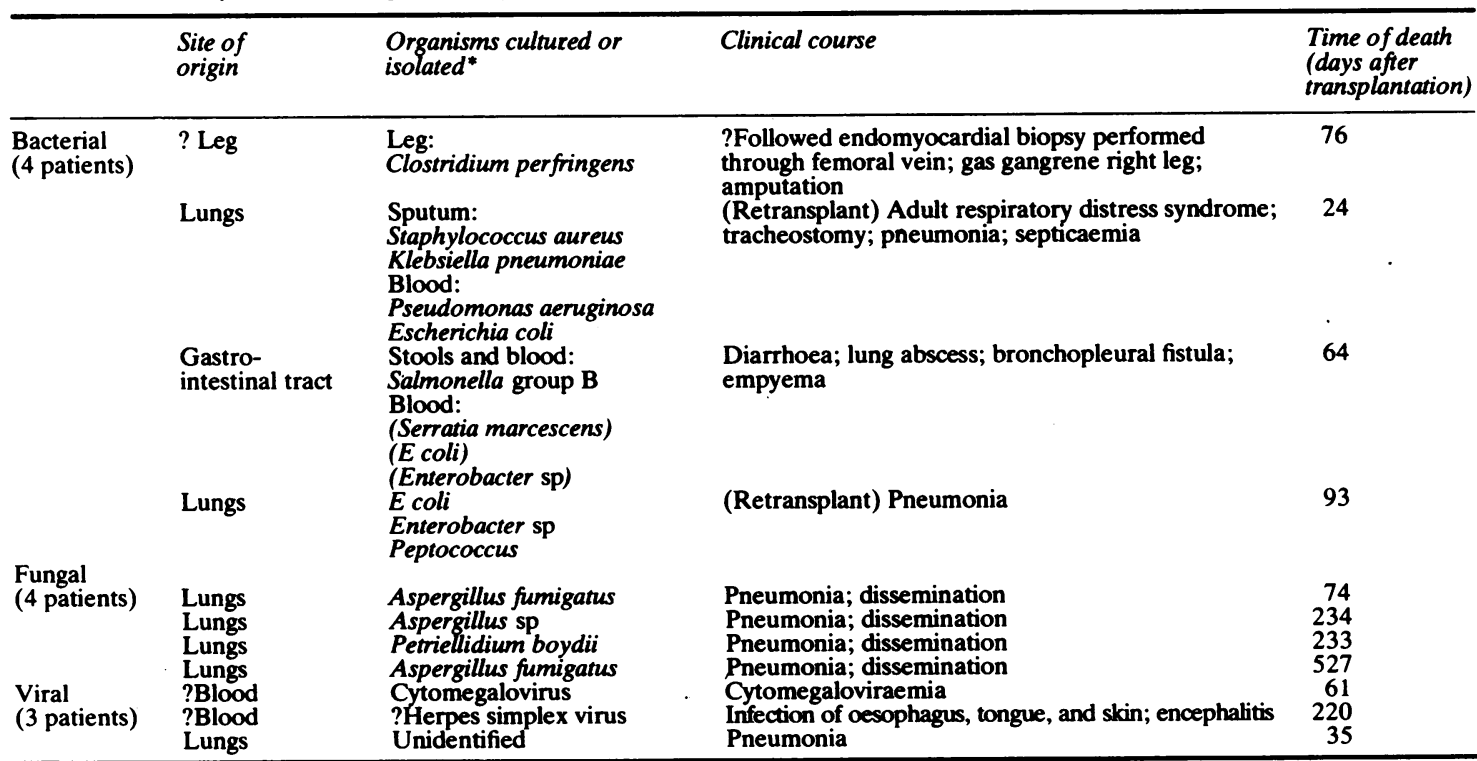

*The significance of organisms in parentheses remains uncertain. 
Salmonella infection was responsible for one death. The patient developed diarrhoea and pneumonia and had positive blood and stool cultures. A lung abscess formed and ruptured into the pleural cavity, resulting in an empyema.

Fungal pneumonia has been a considerable problem, particularly with Aspergillus sp. Petriellidium boydii was found at necropsy in one patient, the findings suggesting primary infection of the lungs with haematogenous dissemination to the brain (fig 1 ), kidneys, and skin. ${ }^{4}$

Fatal viral infections were thought to have occurred in three patients, though the evidence was inconclusive in two. In one there were pathognomonic inclusion bodies of cytomegalovirus in many organs at necropsy. In a second patient inclusion bodies of a herpetic type were seen in several organs, but although the patient died with clinical and histological encephalitis no virus was isolated from the cerebrospinal fluid or from the brain. The third patient developed a severe pneumonia, though no micro-organisms could be cultured; at necropsy there were histological features which supported a diagnosis of viral pneumonia. Evidence of herpesvirus infection and of cytomegalovirus infection were present in about $40 \%$ of patients dying of other causes. ${ }^{4}$

\section{NON-FATAL INFECTIONS}

Non-fatal infections are listed in table 3. Again, the lung was the most common site of infection, being affected in a quarter of the cases. Certain cases are worthy of comment.

Eighteen months after heterotopic heart transplantation endocarditis caused by Staphylococcus aureus developed on an aortic valve prosthesis in the patient's own heart; antibiotic treatment was unsuccessful. The prosthesis was removed, the recipient's left ventricle being partially resected and excluded from the circulation. The patient made an excellent recovery, since when he has been symptom free; over seven years later he is our longest survivor. ${ }^{5}$

Two patients developed severe postoperative sternal wound infections, both of which were extremely difficult to eradicate. In one the original infecting organism was Staphylococcus aureus, but subsequently seven further organisms were grown from discharging sinuses in this region. During the course of two years the patient underwent nine operative procedures in an attempt to eradicate this infection. Chronic discharging sinuses remained for some 36 months but then spontaneously healed, the patient dying of chronic rejection in his fifth postoperative year. In the second patient the original infecting organism remains uncertain, though Enterobacter sp and Staphylococcus epidermidis were the first organisms cultured from the pus exuding from the wound. Eight further organisms, including Aspergillus sp and Clostridium perfringens, were cultured subsequently. The patient underwent three surgical drainage procedures before the infection

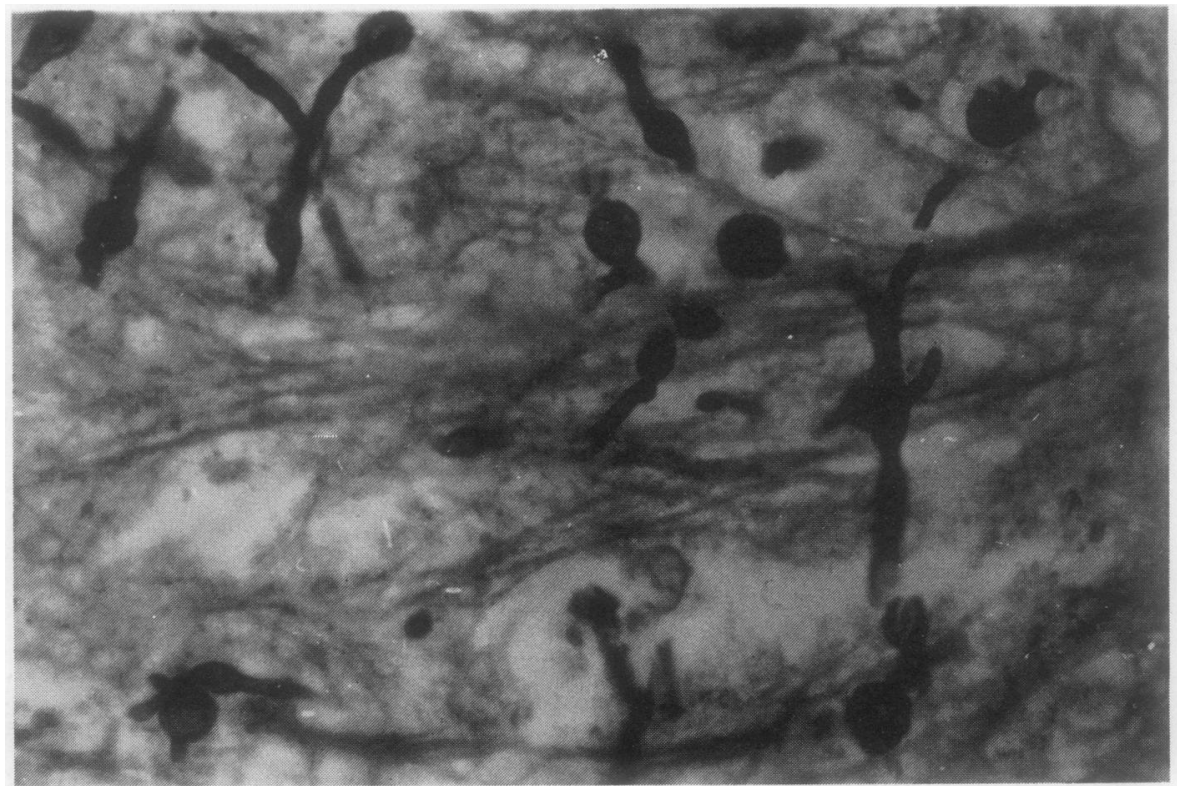

Fig 1 Area of necrosis in the brain containing septate hyphae of Petriellidium boydii; the latter show multiple vesicular expansions. (Methenamine silver, $\times 500$.) 
Table 3 Non-fatal infections after heterotopic cardiac transplantation

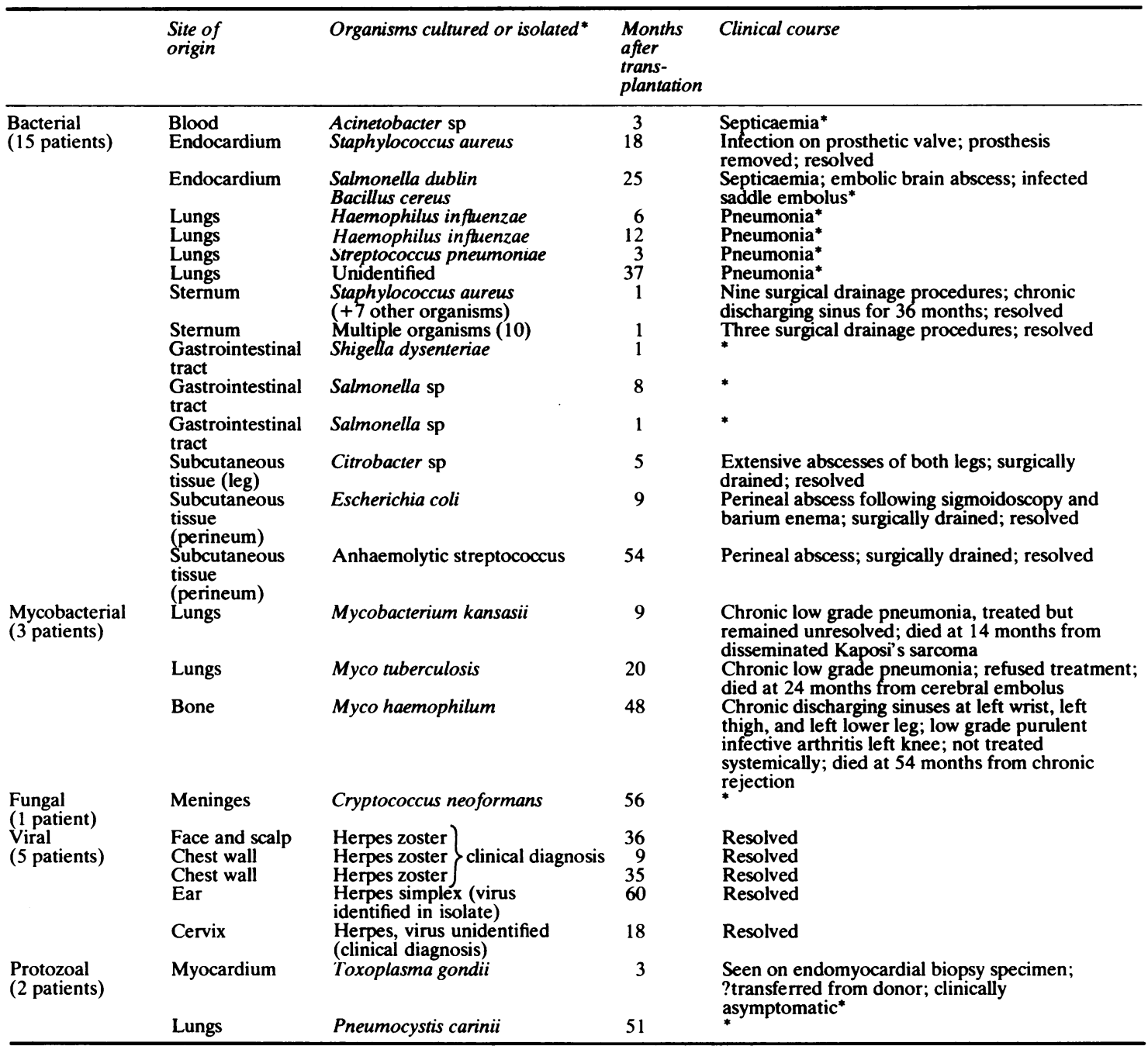

${ }^{*}$ Resolved with treatment.

was eradicated; he remains alive and well almost seven years later.

Myobacterial infection has become an important problem and has proved difficult to treat adequately in these immunosuppressed patients. One patient developed a cavity in the right lung, seen on a chest radiograph 20 months after transplantation, but refused further investigation and treatment, dying four months later from a cerebral embolus. At necropsy Mycobacterium tuberculosis was isolated from the cavity. In a second patient chronic Myco haemophilum infection of limb bones occurred and persisted for several months before the patient died of chronic rejection almost four and a half years after transplantation. Myco kansasii was responsible for a chronic lung infection with empyema in a third patient, who subsequently died 14 months after transplantation from disseminated Kaposi's sarcoma.

Minor herpes simplex infections are very common in immunosuppressed patients, but herpes zoster has also occurred on three occasions, though it has not become disseminated.

Toxoplasmosis was found on endomyocardial biopsy of both donor and recipient hearts in one patient (fig 2), though at no time did the patient develop clinical signs of disseminated infection. ${ }^{6}$ While the infection could have been opportunistic, two other possibilities must be considered. Firstly, the patient's idiopathic cardiomyopathy may have 


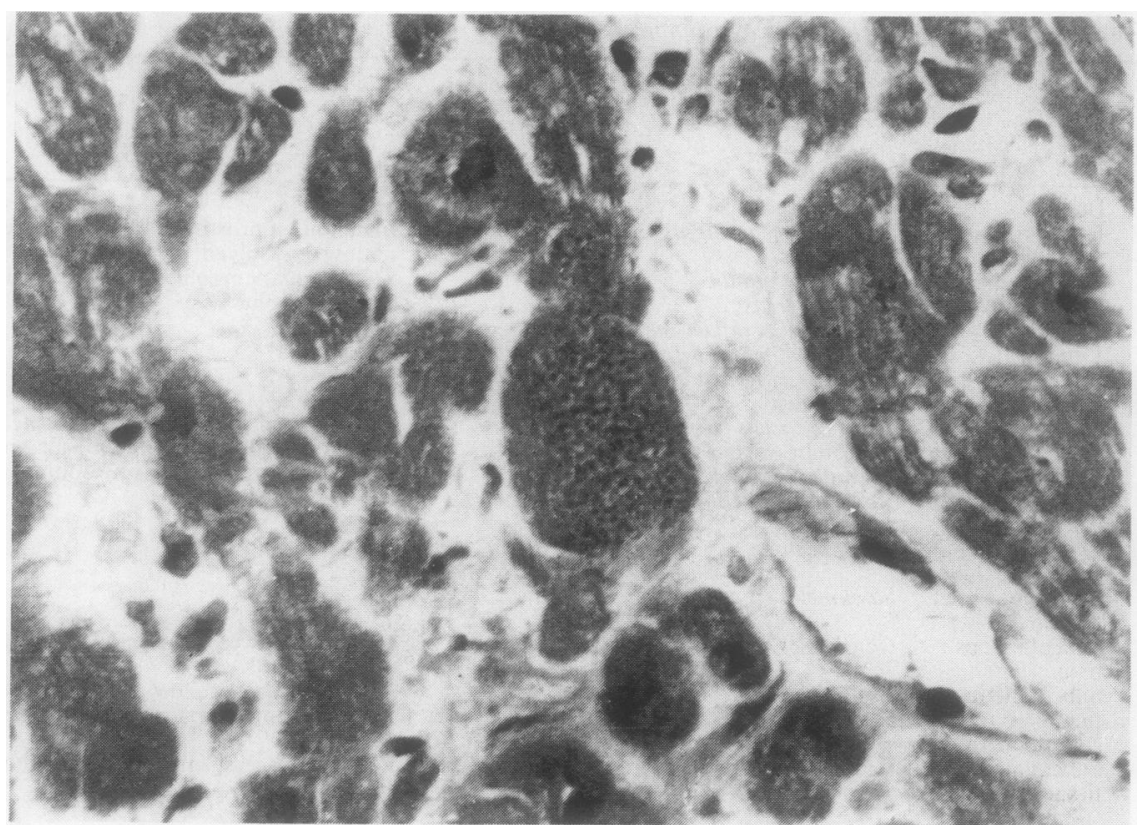

Fig 2 Donor heart biopsy specimen six weeks after transplantation; the swollen myofibre in the centre of the picture contains many dark staining toxoplasmas. (Haematoxylin and eosin, $\times 500$.)

been due to toxoplasmosis; an absence of toxoplasma antibodies before transplantation and a raised titre after transplantation (1/1024), however, argue against prior infection in the recipient. Secondly, the donor could have had toxoplasmosis, the organism being transferred with the donor heart. The donor did have a mildly raised antibody titre $(1 / 256)^{7}$ to toxoplasma so the recipient could have been infected from the donor, although the organism was not seen in endomyocardial biopsy specimens taken in the first month. After treatment, the organism was not seen again on biopsy and the recipient's antibody titres fell to lower levels.

That immunosuppressed patients remain at risk from serious infection even when receiving low doses of drugs is illustrated by one of our patients, who during the fifth year after transplantation developed Pneumocystis carinii pneumonia followed shortly by cryptococcal meningitis; his local physicians successfully treated both episodes.

\section{Discussion}

In patients undergoing heterotopic heart transplantation at Groote Schuur Hospital infection is the major cause of death during the first year after transplantation. The Stanford group has reported an even higher proportion of deaths from infection $(58 \%) .^{3}$ Whether the greater incidence of fatal infection at Stanford is related to differences in the immunosuppressive regimen used at the two centres is uncertain, though possibly a rather greater emphasis has been placed on rabbit antithymocyte globulin at Stanford than in Cape Town. ${ }^{12}$

Our impression has been that during the first three months after transplantation infection not infrequently follows increased immunosuppressive treatment in patients undergoing acute rejection episodes, particularly if such episodes are repeated or prolonged. After three months infectious episodes would appear to be less clearly related to the level of immunosuppressive treatment.

The lung was clearly the most common site for infection in our series, though not infrequently dissemination took place (tables 2 and 4). A higher incidence of purely pulmonary infections has been reported from Stanford with a lower incidence of disseminated infection (table 5). ${ }^{3}$ Minor differences between the two series include a greater number of urinary tract infections at Stanford and of bone infections at Groote Schuur. None of these differences would appear to be related to the different type of operation performed at Stanford (orthotopic as opposed to heterotopic transplantation).

The causal organisms responsible for infectious episodes at the two centres are very similar, bacterial infection accounting for about $60 \%$ in both series. $^{3}$ 
Table 4 Site of presentation of non-fatal infections after heterotopic cardiac transplantation

\begin{tabular}{lll}
\hline Site & $\begin{array}{l}\text { No (\%) of } \\
\text { episodes }\end{array}$ & $\begin{array}{l}\text { No of } \\
\text { patients }\end{array}$ \\
\hline Blood & $1(4)$ & 1 \\
Lung & $7(26)$ & 6 \\
Skin & $4(15)$ & 4 \\
Bone & $3(12)$ & 2 \\
Gastrointestinal tract & $3(12)$ & 3 \\
Subcutaneous tissue & $3(12)$ & 2 \\
Endocardium & $2(7)$ & 2 \\
Myocardium & $1(4)$ & 1 \\
Brain or meninges & $1(4)$ & 1 \\
Cervix & $1(4)$ & 1 \\
\cline { 2 - 2 } & $26(100)$ & \\
\hline
\end{tabular}

Table 5 Comparison of sites of infection at Groote Schuur Hospital (GSH) and Stanford Medical Center (SMC)

\begin{tabular}{lcc}
\hline Site of infection & GSH (\%) & SMH (\%) \\
\hline Disseminated & 29 & 12 \\
Lungs & 24 & 45 \\
Bone & 8 & 1 \\
Central nervous system & 3 & 4 \\
Urinary tract & 0 & 7 \\
Other & 36 & -100 \\
\cline { 2 - 3 } Total & 100 & $\simeq 100$ \\
\hline
\end{tabular}

Several unusual organisms were seen in the present series. Petriellidium boydii is a rare fungus which is usually responsible for localised soft tissue mycetomas. When our patient died of this infection only three previous reports of disseminated petriellidosis had been published. Steroids had been administered to all three patients, in one as immunosuppression for a renal allograft and in two for lupus nephritis. ${ }^{8}$

Three patients developed mycobacterial infections, none of which were fatal, though all three patients died while still infected. The susceptibility of immunocompromised patients to infection with Myco tuberculosis has long been recognised ${ }^{9}$ and the number of reports of infection caused by mycobacteria other than Myco tuberculosis is growing. ${ }^{9-12}$ Myco haemophilum was first isolated relatively recently and has subsequently been described as an infective agent in a small number of immunosuppressed patients. ${ }^{12}$ Myco kansasii is a relatively common cause of pulmonary disease in certain geographical areas $;^{13}$ it has been described previously in immunosuppressed patients and in those with malignancy and haematological disorders, ${ }^{10}$ in whom it is associated with a high death rate.

In the present series the incidence of death due to infection was five times greater in patients over the age of 35 years than in the younger patients $(34 \% v$ $7 \%)(p<0.05)$. There were also significantly more infectious episodes in patients with ischaemic heart disease as their underlying cardiac condition (22 episodes in 29 patients) than in patients with cardiomyopathy (five in 17 patients) $(p<0.01) .{ }^{14}$ Eighty per cent of the episodes of acute pneumonia were in patients with ischaemic heart disease. The higher incidence of infection in ischaemic heart disease patients may well be related to their greater mean age (41 years compared with 30 years for those with cardiomyopathy).

We found a high incidence of infectious complications in patients who for one reason or another did not comply with medical advice and instructions. On occasion this was due to a mild depressive disorder, but more frequently it was due to a casual approach or even irresponsibility on the part of the patient. The possible reasons for non-compliance will be discussed elsewhere. ${ }^{15}$

The operation of heterotopic heart transplantation requires insertion of a graft of prosthetic material, such as Dacron, between donor and recipient pulmonary arteries. The presence of prosthetic material in an immunosuppressed patient might be associated with a risk of infection but so far no such complication has occurred.

Infection remains the major cause of death and a major cause of morbidity during the first year after transplantation. If the patient is to be given the best chance of long term survival, the clinician must be observant for symptoms and signs of infection, clinical investigation in suspicious cases must be urgent and thorough, laboratory investigation must include a search for unusual micro-organisms not frequently met in non-immunocompromised patients, and treatment must be early and aggressive.

The authors thank the many members of the medical, nursing, and paramedical staff of Groote Schuur Hospital and the University of Cape Town Medical School who have contributed towards the care of patients undergoing transplantation.

\section{References}

' Baumgartner WA, Reitz BA, Oyer PE, et al. Cardiac homotransplantation. Curr Probl Surg 1979;16:3-16.

${ }^{2}$ Barnard CN, Barnard MS, Cooper DKC, et al. The present status of heterotopic cardiac transplantation. $J$ Thorac Cardiovasc Surg 1981;81:433-9.

${ }^{3}$ Jamieson SW, Oyer PE, Reitz BA, et al. Cardiac transplantation at Stanford. Heart Transplantation 1981;1:86-92.

${ }^{4}$ Uys CJ, Rose AG, Barnard CN. The pathology of human cardiac transplantation. S Afr Med J 1979;56:887-96.

${ }^{5}$ Losman JG, Curcio A, Barnard CN. Normal cardiac function with a hybrid heart. Ann Thorac Surg 1978;26:177-84. 
${ }^{6}$ Rose AG, Uys CJ, Novitzky D, et al. Toxoplasmosis of donor and recipient hearts following heterotopic cardiac transplantation. Arch Pathol Lab Med 1983;107:368-73.

'Beverley JKA, Beattie CP. Standardisation of the dye test for toxoplasmosis. J Clin Pathol 1952;5:350-3.

${ }^{8}$ Walker DH, Adamec T, Krigman M. Disseminated petriellidosis (allescheriosis). Arch Pathol Lab Med 1978;102: 158-60.

${ }^{9}$ King EQ, Johnson JB, Batten GS, et al. Tuberculosis following cortizone therapy. JAMA 1951;147:23841.

${ }^{10}$ Fraser DW, Buxton AE, Naji A, et al Disseminated Mycobacterium kansasii infection presenting as cellulitis in a recipient of renal homografts. Am Rev Respir Dis 1975;112:125-9.

"Graybill JR, Silva J, Fraser DW, et al. Disseminated myobacteriosis due to Mycobacterium abscessus in two recipients of renal homografts. Am Rev Respir Dis 1974:109:4-10.

12 Mezo A, Jennis F, McCarthy SW, et al. Unusual mycobacteria in five cases of opportunistic infections. Pathology 1979;11:377-84.

${ }^{13}$ Resnikov M. Atypical mycobacteria, their classification, identification and etiological significance. Med J Aust 1970;i:553-7.

${ }^{14}$ Lanza RP, Cooper DKC, Boyd ST, et al. A comparison of patients with ischemic, myopathic and rheumatic heart disease as cardiac transplant recipients. $\mathrm{Am}$ Heart $J$ (in press).

${ }^{15}$ Cooper DKC, Lanza RP, Nash ES, et al. The problem of non-compliance in recipients of cardiac transplants. Heart Transplantation (in press). 